\title{
GRID INTEGRATION STUDIES: ADVANCING CLEAN ENERGY PLANNING AND DEPLOYMENT
}

\author{
GREENING THE GRID
}

Integrating significant variable renewable energy (VRE) into the grid requires an evolution in power system planning and operation. To plan for this evolution, power system stakeholders can undertake grid integration studies. A grid integration study is an analytical framework for evaluating a power system with high levels of VRE resources, such as solar and wind. A grid integration study simulates the operation of the power system under different future VRE penetration scenarios, identifies reliability constraints, and determines the relative cost of actions to integrate VRE. Grid integration studies focus at the system level, providing policymakers, power system operators, and regulators with insights about the impacts and solutions associated with achieving higher shares of wind and solar power in the electricity mix. Example questions a grid integration study can answer include:

- What are the tradeoffs among new sites for VRE generation and/or transmission to meet future demand and achieve VRE targets?
- How will different VRE penetration scenarios impact power system operations, emissions, and costs?

- What institutional or operational actions and investments are needed to achieve a certain VRE penetration target, and what are the relative costs of those actions?

- How will different renewable energy scenarios impact grid stability following a disturbance?

\section{TYPES OF GRID INTEGRATION STUDIES}

Grid integration studies fall into three general categories: capacity expansion, production cost, and power flow studies, as summarized in Table 1. The choice of which study to implement depends on the questions that are most applicable to a power system's context and priorities.

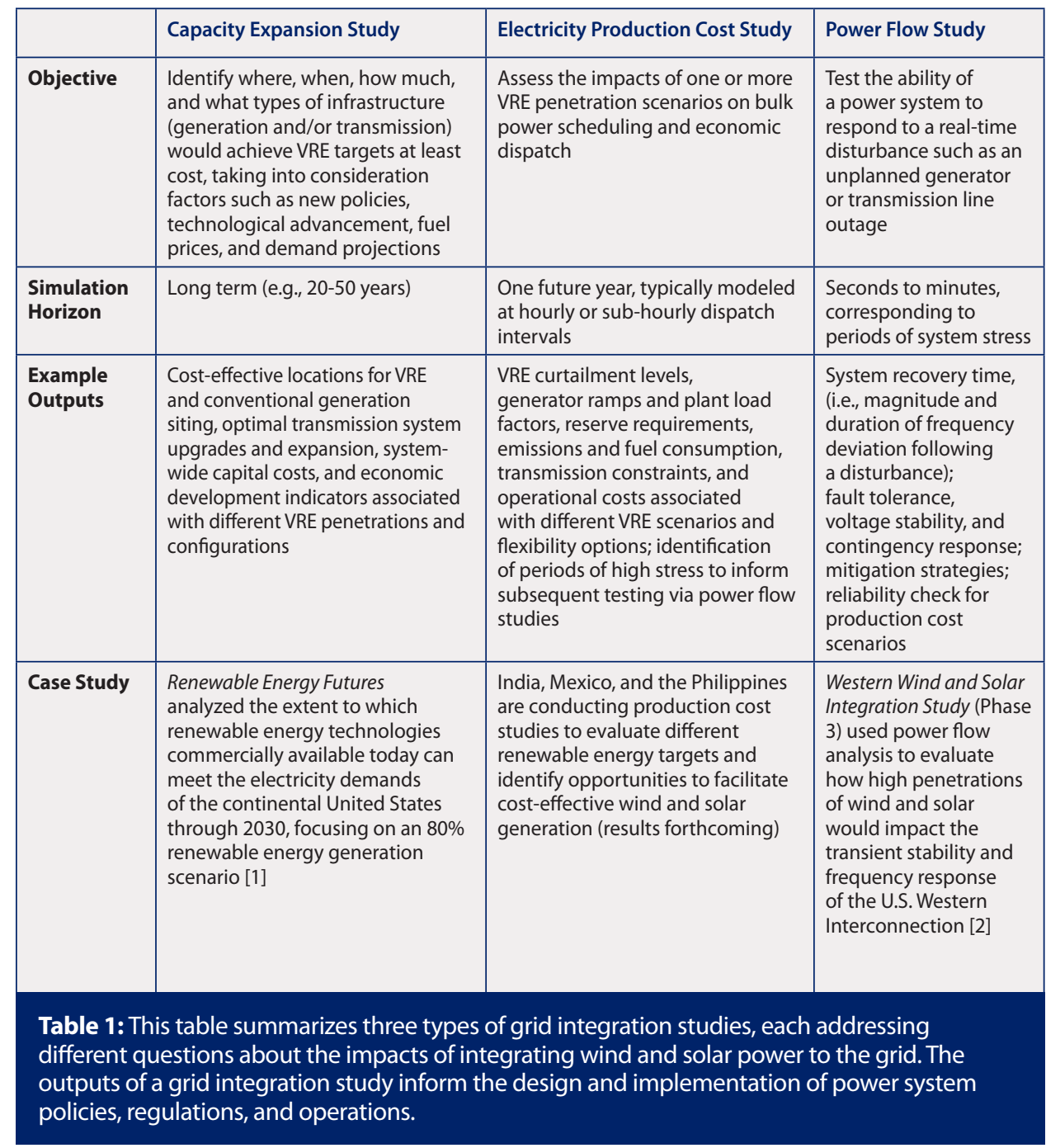

\section{THE ROLE OF A TECHNICAL REVIEW COMMITTEE}

A grid integration study that engages a broad array of stakeholders contributes to robust, credible, and actionable planning that reflects industry and policymaker concerns. A technical review committee (TRC) is one mechanism to facilitate productive stakeholder engagement in a grid integration study. Composed of power system policymakers, regulators, operators, VRE and conventional plant owners, utilities, environmental and public advocates, technical experts, and other organizations, the TRC provides rigorous peer-review and expert input at multiple points throughout the execution of a grid integration study. The TRC's roles include determining the study objectives and assumptions, defining scenarios, reviewing the modeling team's methods and data sources, interpreting and validating results, and linking study results with policy and regulatory processes.

While the members of a TRC may not be involved in day-to-day modeling and analysis, they provide guidance for the core modeling team, whose responsibilities include assembling and validating input data, constructing models, analyzing and verifying results, and compiling technical documentation to communicate findings. The modeling team is typically comprised of staff from power system operators, energy agencies, and other stakeholders with technical expertise in power systems or electrical engineering, power flow modeling, power system operations, and the mechanisms that drive electricity markets. 


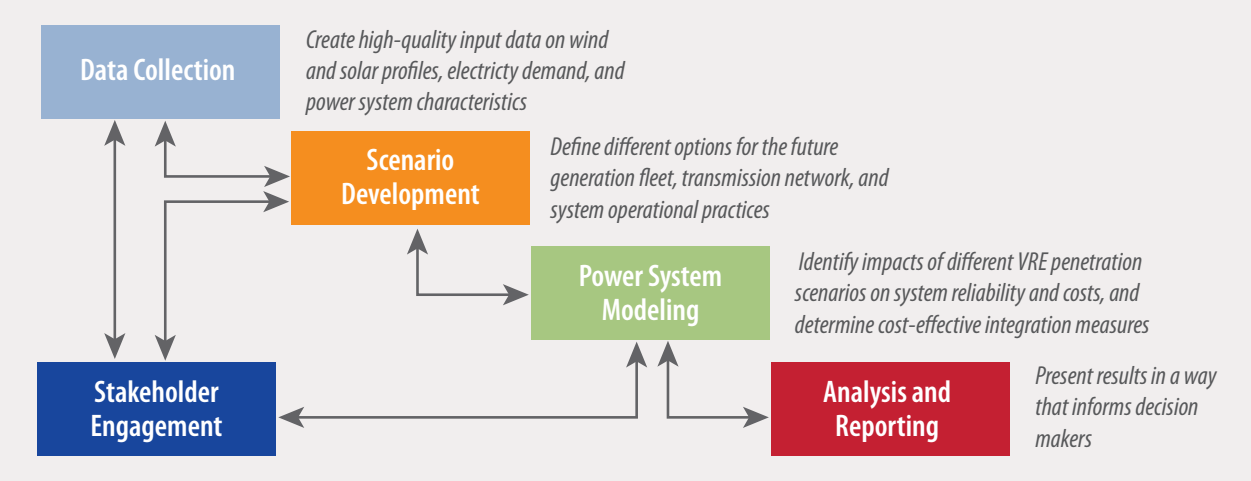

Figure 1: Several iterative activities are involved in implementing a grid integration study. Stakeholder engagement (for example, through a Technical Review Committee) is a crucial component throughout each phase of the study. See [4] for a more detailed figure that includes decision points and recommended actions for each activity.

\section{CONDUCTING A GRID INTEGRATION STUDY}

Regardless of type, conducting a grid integration study involves several iterative activities, as illustrated in Figure 1. Collecting data on wind and/or solar resources, demand, and the characteristics of the existing and planned power system is a fundamental step that provides modelers with the information they need to perform the analyses and generate results.' Scenario development articulates the questions of greatest interest for the study and should be informed by stakeholder input. Typically, study scenarios are established in relation to a base or business-as-usual case, under which policies and operational practices will remain relatively unchanged from current practices with respect to their treatment of VRE.

Following these foundational actions, analysts model the power system under different scenarios and perform a variety of assessments to appropriately quantify costs, reliability, and/or other impacts. The development or procurement of an appropriate modeling platform (specific to capacity expansion, production cost, or power flow studies) is an important component of this step. The final step is analysis and reporting of study results, with the goal of providing actionable information to decision makers that allows them to translate the outputs of a grid integration study into effective policy, regulation, and system operation.

Conducting a grid integration study is a significant undertaking. The timeframe as well as the cost depend on the scope of the study, extent of stakeholder engagement, data availability, and level of capacity building needed to develop modeling expertise. Stakeholder engagement throughout all phases of a grid integration study will help ensure that study assumptions are grounded in reality and that the results have enough credibility to guide power sector transformation [3].

\section{FROM STUDY TO ROADMAP}

The ultimate goal of a grid integration study is to address stakeholder concerns that a power system can operate reliably and cost effectively under high-VRE scenarios and give decision makers the information and confidence they need to set and meet ambitious VRE and climate change mitigation targets. Based on the results of a grid integration study, power system planners can prioritize the most costeffective actions to meet their grid integration goals, and identify the implementation steps, costs, timeframe, and responsible party for each action.

In addition to identifying highest-value integration actions, a grid integration study will likely raise additional questions that may warrant further analysis. Subsequent analyses can build on the framework developed for an initial study to analyze additional timescales, scenarios, and geographic regions or to focus on broader energy systems analysis that considers the combined impacts of VRE on the transmission, distribution, natural gas, and transportation systems. With rigorous technical oversight and robust stakeholder engagement, a grid integration study can serve as a powerful long-term tool to guide decision makers in planning and implementing well-informed renewable energy policies.

\footnotetext{
. See the "Grid Integration Studies: Data Requirements" fact sheet for more information about data requirements for a grid integration study.
}

\section{REFERENCES}

[1] National Renewable Energy Laboratory. (2012). Renewable Energy Futures Study. NREL/ TP-6A20-52409.

[2] Miller, N., S. Shao, S. Pajic, and R. D'Aquila. (2014). Western Wind and Solar Integration Study Phase 3 - Frequency Response and Transient Stability. NREL/SR-5D00-62906.

[3] Federal Electricity Regulatory Commission. (2016). Staff White Paper on Guidance Principles for Clean Power Plan Modeling. Docket No. AD16-14-000.

[4] Holttinen, H., A. Orths, H. Abildgaard, et al. (2013). Expert Group Report on Recommended Practices (16. Wind Integration Studies). Edited by Hannele Holttinen. Technical Report, IEA Task 25.

Written by J. Katz and I. Chernyakhovskiy, National Renewable Energy Laboratory

Greening the Grid provides technical assistance to energy system planners, regulators, and grid operators to overcome challenges associated with integrating variable renewable energy into the grid.

\section{FOR MORE INFORMATION}

Jennifer Leisch

USAID Office of Global Climate Change

Tel: +1-202-712-0760

Email: jleisch@usaid.gov

Jaquelin Cochran

National Renewable Energy Laboratory

Tel: +1-303-275-3766

Email: jaquelin.cochran@nrel.gov

Greening the Grid is supported by the U.S government's Enhancing Capacity for Low Emission Development Strategies (EC-LEDS) program, which is managed by the U.S. Agency for International Development (USAID) and Department of State with support from the U.S. Department of Energy, U.S. Environmental Protection Agency, U.S. Department of Agriculture, and U.S. Forest Service.

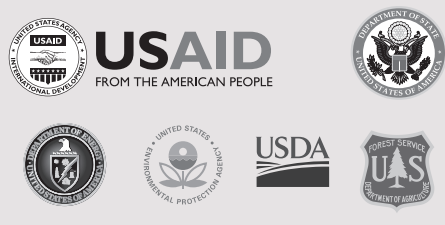

greeningthegrid.org | ec-leds.org NREL/TP-6A20-66504 July 2016 